\title{
Accident Neurosis Revisited
}

\author{
RICHARD MAYOU
}

Considerable increases over recent years in the number and size of compensation, insurance benefit and social security payments following injury have been reported from many countries for numerous types of medical problem. Many of these awards relate to pain and suffering and also to specific psychiatric complications. It is important that psychiatrists who are asked to assess the significance of psychological factors, as both causes and consequences, understand the ways in which accidental and other injuries may cause psychiatric problems and affect the quality of victims' lives, and the ways in which insurance and legal processes influence such consequences. It is also essential that they are able to explain and justify our views and methods to other doctors, employers, lawyers and all others who may be involved. Unfortunately, psychiatric texts are generally unhelpful and this has had adverse effects for clinical care and medicolegal practice.

Polemically argued in the ' 50 s and ' 60 s by Foster Kennedy and Henry Miller (Miller, 1961), accident neurosis (compensation neurosis and many synonyms) has often been seen by doctors and lawyers as a syndrome of psychological symptoms, unexplained physical complaints and excessive disability, which has a psychological aetiology, is motivated by hopes of financial and other rewards, and which shows considerable improvement following the settlement of compensation. This traditional view was never generally accepted and is now totally outdated. Although it lacks credibility, it remains influential with doctors and with lawyers, as is demonstrated by a recent review of whiplash (Pearce, 1994), and is clearly described in a very competent consultation paper by the British Law Commission (Law Commission, 1995).

It is unfortunate that clinical and legal prejudices, inadequate research and lack of any forum for proper debate have prevented consideration of the psychological effects of accidents and other personal injuries in the same manner that the consequences of physical illness, and indeed of life events in general, are now being investigated and understood. Instead, much of the literature on compensation is based on experience with highly atypical samples of litigants (and especially those involved in disputed cases), and there have been few prospective studies of representative samples using the quantitative measures that are now generally expected in psychiatric research.

If accident neurosis is now a term which should have no more than historical interest, we require a modern formulation of the possible role of compensation as a cause of psychosocial handicap. This should take account of recent advances both in psychiatric knowledge and research methodology in general, changes in the social and legal context and specific research on trauma and its consequences. This paper considers each of these issues in turn and presents conclusions for a modern view of 'accident neurosis'.

\section{Recent advances in psychiatric concepts and methodology}

Very considerable research has examined the psychological impact of major life events in general; in particular there have been many descriptions of the consequences of acute and chronic physical illnesses (Mayou \& Sharpe, 1995). Anxiety and depressive symptoms are common, and the most frequent psychiatric diagnoses are adjustment disorders, depression, and anxiety disorders. However, other psychiatric disorders also occur and functional somatic symptoms are frequent.

Following major physical illness, a quarter or a third of people describe distress and disability which is significantly greater than usual and may therefore be seen as 'disproportionate'. The severity and patterns of such symptoms are determined more by individual vulnerability factors than by the nature of the physical disorder. It is rare for exaggeration or simulation to be cited as explanations, and complications are best understood as the result of the interaction of physical impairment, the individual meaning of the illness, social circumstances, psychological vulnerability and distress, and the nature and quality of medical care. In this context it is important to emphasise that individual psychological reactions and other aspects of outcome are substantially determined by the reactions 
of other people, family, friends, employers and, not least, doctors. Iatrogenic factors can be of considerable significance, and this is especially so in relation to a number of poorly understood syndromes of functional symptoms (Mayou \& Sharpe, 1995).

\section{Operational definitions}

Concepts of psychiatric disorder are very different to those prevailing at the times that the concepts of accident neurosis (and many other traditional syndromes) were being promulgated. Psychiatric disorder is now defined in terms of operational diagnostic descriptions in the ICD and DSM classifications. The main principle underlying both classifications is that of operationally defined symptom criteria (with the important exception described below).

The introduction of the category of posttraumatic stress disorder (PTSD) in DSM-III (American Psychiatric Press, 1980) following increasing clinical interest and research on the consequences of combat and disasters (especially awareness of the problems of Vietnamese war veterans) has focused attention on specific symptoms that can be extremely distressing and remarkably persistent. Overall, this has been valuable in recognising the validity of clinically major psychiatric morbidity. However, the premature introduction and widespread acceptance of an operational definition which is still of uncertain validity has restricted understanding and research, over-emphasising certain clinical features at the expense of a neglect of major psychiatric comorbidity (especially anxiety and depression (Andreasen, 1995) ).

\section{Changes in the legal and social context}

There have been some changes in the law on personal injury and its interpretation, and rather more substantial changes in the extent and manner that is used. The basic legal issues are described in a recent consultation paper published by the Law Commission of the United Kingdom (Law Commission, 1995), which reviews the psychiatric consequences of personal injury and examines the way in which they have been dealt with in British law. It is a valuable summary of current medical and legal thinking which usefully criticises many widely held misunderstandings, and shows the way towards a more collaborative approach to the issue of compensation.
There has also been a conspicuous increase in litigiousness and in the expectations of victims and of the wider public that those who are believed to have caused injury should both be punished and pay compensation. However, this in many ways regrettable trend should not lead to the conclusion that there has also been a marked, or even any, increase in exaggeration or simulation of distress and disability in relation to individual claims. It is more likely that highly publicised and contentious cases reflect changes in the entirely reasonable social expectations of the patients, their doctors and their employers about the implications of all medical problems which may be seen in a civilised society as justifying some form of compensation for losses. Even so, it is possible, even probable, that changes in expectations have affected individual illness behaviour as one of the many psychosocial determinants of the outcome of injury and illness.

\section{Evidence on psychological reactions to injury}

Much has been written about the consequences of many forms of personal injury (work related, disasters, assault, road traffic accidents, etc.). However, sources and methods are disparate and findings need to be critically considered in the wider context of what is known about psychiatric disorder in relation to life events in general. The large literature covers particular types of medical problem (for example, low back pain) and types of physical and mental injury (for example, combat, disasters, road traffic accidents). Some reports relate to relatively precisely defined groups, others to heterogeneous accident victims seen in emergency departments or medicolegal practice.

Few studies have been specifically designed to answer questions about the role of compensation, but there is consistent evidence that the processes of compensation and insurance benefits should be seen as among the many social influences on course and outcome. For example, extensive research on pain, especially back pain, shows that those with employment injuries are slower returning to work (Greenough \& Fraser, 1989; Leavitt, 1990; Brewin et al, 1991; Philips et al, 1991) and have more work problems than those suffering similar injuries in other circumstances for which compensation is not appropriate (Fordyce, 1988; Leavitt, 1990; Brewin et al, 1991). At the same time, there is also consistent evidence both that the general nature and course of pain and other symptoms are little affected by whether compensation is being sought, and that treatment is frequently effective in those involved in litigation. 
Our own recent prospective study of consecutive attenders with multiple injuries and whiplash injury found few differences between those involved in compensation and those who were not, in terms of symptoms, return to work, mental state outcome or return to social and leisure activities (Mayou, 1995). There is similar evidence from head injury (McKinlay et al, 1983) and other patients suggesting that compensation is not a major determinant of outcome or of response to treatment. In all these studies, as in routine (as opposed to medicolegal) practice, deliberate exaggeration and simulation are rare, though they undoubtedly occur. They are especially conspicuous in the small proportion of disputed and controversial cases.

There has been much argument as to whether settlement of compensation proceedings is followed by a marked improvement in physical symptoms and reduction in disability. All those involved in medical legal work can describe colourful examples of dramatic recovery, but careful prospective studies have consistently found little evidence that such improvements are common. Symptoms and disabilities present at the time of settlement generally have poor prognosis over long-term follow-up (Mendelson, 1995).

\section{The significance of anger}

One feature of the psychological response to illness and injury has not attracted the systematic attention it deserves. Anger is not uncommon in physical illness (Fernandez \& Turk, 1995) and is a prominent reaction of many innocent victims of trauma; anger about the suffering, anger towards those responsible, and anger about the lack of recognition of the suffering and disability. Anger influences attitudes to the pursuit of compensation; it is often focused on the lack of concern or apology by those believed to be responsible rather than on gaining maximum financial reward. For example, in medical malpractice, the way in which the complaint is handled is a very important determinant as to whether any litigation is pursued (La Rae et al, 1994).

\section{Iatrogenic factors}

Emphasis on patients' motivation has often obscured consideration of the role of iatrogenic medical and legal factors. There is increasing acceptance that standard medical care is often ineffective, and, indeed; harmful in a number of common but poorly understood traumatic syndromes, for example low back pain (Ellis, 1995) and whiplash neck injury (Teasell \& Shapiro, 1993). In addition, doctors' uncertainty, inconsistency and feelings of therapeutic helplessness contribute to patients' own uncertainty, excessive caution and demoralisation. Similarly, legal processes which are protracted, frustrating and widely seen as unsatisfactory must be expected to hinder rather than promote return to normal life.

\section{Specific syndromes}

Apart from accident neurosis a number of alleged specific syndromes have attracted particular attention as reasons for compensation, for example environmental allergy (David \& Wessely, 1995), Gulf War and Desert Storm syndrome (Persian Gulf Veterans Coordinating Board, 1995), postconcussion syndrome ( Jacobson, 1995), whiplash neck injury (Teasell \& Shapiro, 1993) and repetitive strain injury (Reilly, 1995). They are diverse in nature, of generally uncertain validity, and are usually defined in aetiological terms. In contrast to older syndromes which were coined by doctors, they are increasingly named and promoted by sufferers. It is unfortunate that political influences, distorted media coverage and excessive medical reticence have made rational discussion difficult. The resultant public unwillingness to accept that symptoms can be real even when psychologically determined, that they are common and that physical and psychological aetiological factors often interact, has been deeply harmful.

Not only has there been misleading press and television coverage of such problems, but governments and national organisations have been wary of causing offence by promoting research and proper discussion. For example, a recent official American report (Persian Gulf Veterans Coordinating Board, 1995) on Desert Storm syndrome (the American equivalent of the British Gulf War syndrome) considers and rules out many physical aetiologies but makes not a single reference to psychological factors whose importance in the authors' minds can only be guessed at by their systematic exclusion of all possible physical explanations. We need to rigorously review the definition and validity of each individual syndrome.

A common (and still controversial) example of a specific clinical syndrome is whiplash neck injury. It has frequently been said (and is widely believed) that persistent whiplash neck symptoms are substantially determined by the prospect of compensation (Pearce, 1994). However, several substantial recent reviews (Quebec Task Force on WhiplashAssociated Disorders, 1995; Shapiro \& Roth, 1993; Teasall \& Shapiro, 1993) and research indicate that 
there is a consistent clinical picture and that physical causes are responsible for the acute neck syndrome and underlie the chronic syndrome. It is also evident that the psychological and social variables affect presentation and course, as they do in other musculo-skeletal disorders, and indeed physical illness in general.

Evidence of the clinical validity of a number of many other proposed syndromes is much less convincing. There is no obvious medical difference between them and many other ill-defined functional somatic problems (Mayou et al, 1995); none the less they refer to real suffering. The over-emphasis on entitlement to compensation in relation to several of these disorders has had unfortunate consequences for individuals, for medicine and for public policy. For example, it would be more satisfactory to consider cases of upper limb symptoms which have some relationship with occupational demands in individual clinical terms, rather than as examples of an alleged syndrome of repetitive strain injury which lacks clinical or aetiological homogeneity or validity (Reilly, 1995). The more sophisticated multicausal formulation opens the way to sensible planning of work procedures, appropriate medical care and a more individual and appropriate role for compensation. Similar arguments apply to several other syndromes which have been promoted by bewildered sufferers and committed propagandists and have been given a spurious respectability by case law and public reluctance to allow dispassionate discussion.

\section{The process of compensation}

There is a general lack of knowledge about the ways in which people seek compensation and about outcome. A recent report on behalf of the United Kingdom's Law Commission interviewed a large number of recipients of awards from insurance companies and concluded that the amounts of settlement seemed to be modest in relation to injuries and losses, that they were often delayed, that they were spent appropriately, and indeed that there was strong evidence that losses, especially long-term losses, were underestimated (Law Commission, 1994).

Our own prospective study of 96 subjects who pursued compensation claims found great dissatisfaction at the slowness, secrecy and unsatisfactory outcome of claims over a period of 6 years (Mayou, 1995). There was little evidence of pursuit of claims for maximum financial gain, and some people decided that they did not want the bother of claiming, or they dropped or settled claims at an early stage. Public recognition of suffering and innocence appeared to be important motives for claims. Settlements seemed modest and were used to pay debts or for postponed purchases, rather than for any extravagant or frivolous purpose. Revisiting old views of accident neurosis suggest that they have nothing useful to offer. It is entirely appropriate to be aware of the possibility of exaggeration, simulation and other fraudulent behaviour, but we should see this as uncommon rather than typical.

\section{Conclusions}

The terms accident or compensation neurosis were never completely accepted in psychiatry and are now demonstrably redundant. They should have no place in medical or legal discussion, but are still being used by doctors and lawyers. There are several substantial reasons for current conceptual and clinical difficulties:

(a) A failure to apply what is already well known in relation to physical illnesses in general and to life events of all kinds.

(b) A lack of high quality research on accidents and personal injury and on the significance of compensation.

(c) A recent over-preoccupation in trauma research on the concept of PTSD. Important issues about specific post-traumatic symptoms need to be put in a broader context of our understanding of the psychological consequences of stressful events in general.

(d) A proliferation of new syndromes, mainly promoted by sufferers, which have been exploited by the media. The timidity of government and lack of leadership by psychiatry and medicine have substantially impaired understanding.

(e) A lack of informed debate between doctors and lawyers.

Despite these problems and the substantial gaps in our understanding, it is possible to understand the consequences of personal injury and the role of compensation within what is very well established about the determinants and consequences of trauma, physical illness and stressful events. Psychiatric disorder and psychologically determined effects on behaviour and quality of life can be expected to be common; in a minority they will seem disproportionate to any physical impairment.

We must be prepared to see most of the psychologically determined complications of trauma as 
real and accept the considerable evidence that exaggeration and simulation are uncommon. Since the determinants of individual reactions are multiple (physical, psychological and social), it is essential to understand the meaning of the physical problem to the particular patient. Inevitably, the recognition of innocent suffering implied by compensation and the possible extent of financial reward must colour mental state and behaviour.

In clinical practice, we need to be aware of the commonness of psychological complications, to accept them as real and to give patients the reassurance and the extra help that might be useful. Better informed and more sympathetic care can be expected to result in less dissatisfaction and improved outcome. A proportion of subjects can be expected to benefit from the standard psychological interventions and these should be available as soon as problems are recognised. It is also important that legal and insurance processes recognise suffering and respond quickly, effectively and courteously. It is highly probable that simple measures would be helpful for most people. Many could be accomplished without extra costs and often with significant savings. Indeed, greater recognition of suffering might reduce the demand for financial compensation.

We must move from a preoccupation with a small minority of sufferers whose complaints are not wholly genuine, to examining the ways in which we could respond to victims' problems with better medical treatment and more efficient and effective procedures for compensation and benefits. Improved understanding depends in part upon further research. It depends much more on a determined effort by doctors to debate the issues fully and publicly. We need to influence the law, government and institutions and the general public. Perhaps the first step should be for psychiatrists to inform themselves and be prepared to provide an expert and informed opinion in individual cases and in the wider debate.

\section{References}

Amerucan Psychiatruc Press (1980) Diagnostic and Statistical Manual of Mental Disorders (3rd edn) (DSM-III). Washington, DC: APA.

Andreasen, N. (1995) Post-traumatic Stress Disorder. Psychology, biology and the Manichaean warfare between false dichotomies. American Journal of Psychiatry, 152, 963-965.
Brewin, C. R., Robson, M. J. \& ShapiRo, D. A. (1991) Social and psychological determinants of recovery from industrial injuries. Injury, 14, 451-455.

David, A. S. \& Wessely, S. C. (1995) The legend of Camelford: Medical consequences of a water pollution accident. Journal of Psychosomatic Research, 39, 1-9.

ELus, R. M. (1995) Back pain. British Medical Journal, 310, 1220 Fernandez, E. \& TuRK, D. C. (1995) The scope and significance of anger in the experience of chronic pain. Pain, 61, 165-175.

FordYCE, W. E. (1988) Pain and suffering. American Psychologist, 43, 276-283.

Gresnough, C. G. \& Fraser, R. D. (1989) The effects of compensation on recovery from low-back injury. Spine, 14, 947-955.

JACOBson, R R (1995) The post-concussional syndrome: physiogenesis, psychogenesis and malingering: An integrative model. Journal of Psychosomatic Research, 39, 675-694.

LA RAE, I., HUYCKE, R. N. \& HUYCKE, M. M. (1994) Characteristics of potential plaintiffs in malpractice litigation. Annals of Internal Medicine, 120, 792-798.

Law Commission (1994) Personal Injury Compensation: How Much is Enough? A Study of the Compensation Experiences of Victims of Personal Injury. London: HMSO.

(1995) Liability for Psychiatric Ilness. Consultation paper No. 137. London: HMSO.

Lenvitr, F. (1990) The role of psychological disturbance in extending disability time among compensable back injured industrial workers. Joumal of Psychosomatic Research, 34, 447453.

MAYOU, R. A. (1995) Medico-legal aspects of road traffic accidents. Journal of Psychosomatic Research, 39, 781-798.

MAYOU, R., BAss, C. \& SHARPE, M. (eds) (1995) Treatment of Functional Somatic Symptoms. Oxford: Oxford University Press.

MAYOU, R. A. \& ShARPE, M. (1995) Psychiatric illnesses associated with physical disease. Bailliere's Clinical Psychiatry, 1, 201-224.

McKinlay, W. W., Brooks, D. N. \& Bond, M. R. (1983) Postconcussional symptoms, financial compensation and outcome of severe blunt head injury. Journal of Neurology. Neurosurgery and Psychiatry, 46, 1084-1091.

Mendelson, G. (1995) "Compensation neurosis" revisited: Outcome studies of the effects of litigation. Joumal of Psychosomatic Research, 39, 695-706.

MilleR, H. (1961) Accident neurosis. British Medical Joumal, 919-998.

Pearce, J. M. S. (1994) Polemics of chronic whiplash injury. Neurology, 44, 1993-1997.

Persian Gulf Veterans Coordanatng Board (1995) Unexplained illnesses among Desert Storm veterans. Archives of Internal Medicine, 155, 262-268.

Phintrs, H. C., Grant, L. \& Berrowitz, J. (1991) The prevention of chronic pain and disability: a preliminary investigation. Behavioural Research Therapy, 29, 443-450.

QuEarec TASK Force ON WHIPLASH-Associntrd Disorders (1995) Whiplash-Associated Disorders (WAD): Redefining "Whiplash" and its Management. Sociétés de L'Assurance Automobile du Quebec.

ReILLY, P. A. (1995) "Repetitive Strain Injury": From Australia to the UK. Journal of Psychosomatic Research, 39, 783-788.

Shupiro, A. P. \& Roth, R. S. (1993) The effect of litigation on recovery from whiplash. Spine, 7, 531-556.

TEASELL, R. W. \& SHAPIRo, A. P. (1993) Cervical fiexion-extension whiplash injuries. Spine: State of the Art Reviews, 7, 1-571.

Richard Mayou, University Department of Psychiatry, Warneford Hospital, Oxford OX3 7JX

(First received 22 August 1995, final revision 18 October 1995, accepted 11 November 1995) 